\title{
Elevated preoperative peripheral blood monocyte count predicts poor prognosis for hepatocellular carcinoma after curative resection
}

\author{
Shun-Li Shen ${ }^{1 \dagger}$, Shun-Jun Fu ${ }^{1,2+}$, Xiong-Qing Huang ${ }^{3 *}$, Bin Chen ${ }^{1}$, Ming Kuang ${ }^{1}$, Shao-Qiang Li ${ }^{1}$, Yun-Peng Hua ${ }^{1}$, \\ Li-Jian Liang ${ }^{1}$ and Bao-Gang Peng ${ }^{1 *}$
}

\begin{abstract}
Background: Peripheral blood monocyte count is an easily assessable parameter of systemic inflammatory response. The aim of this study was to determine whether monocyte count was prognostic in hepatocellular carcinoma (HCC) following hepatic resection.

Methods: We retrospectively reviewed 351 patients with HCC treated with hepatic resection from 2006 to 2009. Preoperative absolute peripheral monocyte count, demographics, and clinical and pathological data were analyzed.

Results: On univariate and multivariate analysis, elevated monocyte counts ( $\left.\geq 545 / \mathrm{mm}^{3}\right)$, tumor size $\geq 5 \mathrm{~cm}$, non-capsulation, and multiple tumors were associated with poor disease-free survival (DFS) and overall survival (OS). The 1-, 3- and 5-year DFS rates were $58 \%, 41 \%$ and $35 \%$, respectively, for patients with monocyte counts $<545 / \mathrm{mm}^{3}$, and $36 \%, 23 \%$ and $21 \%$ for patients with monocyte counts $\geq 545 / \mathrm{mm}^{3}$. Correspondingly, the 1-, 3- and 5-year OS rates were $79 \%, 53 \%$ and $46 \%$ for monocyte counts $<545 / \mathrm{mm}^{3}$, and $64 \%, 36 \%$ and $29 \%$ for monocyte counts $\geq 545 / \mathrm{mm}^{3}$. Subgroup analysis indicated that DFS after hepatic resection in hepatitis B virus (HBV)-infected patients was significantly better in those with a peripheral blood monocyte counts $<545 / \mathrm{mm}^{3}$, but it did not differ between patients without HBV infection. In addition, DFS was significantly better for patients with a peripheral blood monocyte count $<545 / \mathrm{mm}^{3}$, whether or not cirrhosis was present. Patients with elevated monocyte counts tended to have larger tumors.

Conclusions: Elevated preoperative monocyte count is an independent predictor of worse prognosis for patients with HCC after hepatic resection, especially for those with HBV infection. Postoperative adjuvant treatment might be considered for patients with elevated preoperative monocyte counts.
\end{abstract}

Keywords: Hepatocellular carcinoma, Monocyte, Hepatic resection, Prognosis

\section{Background}

Hepatocellular carcinoma (HCC) is the fifth most common cancer and the third most frequent cause of cancerrelated death [1]. Hepatic resection is one of the most effective treatments for HCC. However, even after hepatic resection, the long-term prognosis has remained far from satisfactory because of the high rate of recurrence.

\footnotetext{
* Correspondence: hxiongqing@21cn.com; pengbaogang@medmail.com.cn ${ }^{\dagger}$ Equal contributors

${ }^{3}$ Department of Anesthesiology, The First Affiliated Hospital, Sun Yat-sen University, Guangzhou 510080, China

'Department of Hepatobiliary Surgery, The First Affiliated Hospital, Sun

Yat-sen University, Guangzhou 510080, China

Full list of author information is available at the end of the article
}

Therapies such as re-operation, percutaneous ablation, and transcatheter arterial chemoembolization (TACE) might be considered for recurrent HCC [2-4]. Unfortunately, however, there are limited or no therapeutic options for a large number of patients when recurrence is found. It is therefore critical to define reliable prognostic factors that may help identify patients at high risk of recurrence. In addition, this group of patients might benefit from postoperative adjuvant therapy against recurrence $[3,4]$.

Prognostic factors identified in previous studies include tumor stage, serum $\alpha$-fetoprotein (AFP), vascular invasion, tumor size, and poor tumor differentiation [2]. Novel immunological and histological biomarkers have 
also been identified, but they tend to be time consuming to measure and do not constitute standard practice. Emerging evidence indicates that peripheral blood cells reflect the inflammatory status of patients, and they are predictors of prognosis in cancer patients. The association between pretreatment peripheral leukocytes (including neutrophils, lymphocytes and platelets) and prognosis has been observed in various cancers, including colon cancer, melanoma and pancreatic carcinoma. In addition, systemicinflammation-based scores such as Glasgow prognostic score (GPS), neutrophil lymphocyte ratio (NLR), and platelet lymphocyte ratio (PLR) have prognostic value in cancer patients [5].

Regarding HCC, preoperative elevated NLR is associated with short disease-free survival (DFS) and overall survival (OS) after hepatectomy or liver transplantation [6,7]. Likewise, increased C-reactive protein or monocyte count has been linked with poor prognosis [8,9]. Monocytes play an important role in innate immunity and exhibit prognostic value in cancers. High pretreatment monocyte count is an independent factor of poor prognosis for patients with colorectal liver metastasis, cervical cancer, melanoma, and HCC [9-12]. In fact, circulating monocytes predict incident cancer and mortality even in healthy individuals [13].

The aim of the present study was to evaluate whether elevated preoperative peripheral monocyte count predicts poor prognosis in HCC patients after hepatic resection, especially in hepatitis $\mathrm{B}$ virus (HBV)-associated $\mathrm{HCC}$.

\section{Methods}

\section{Study population}

We enrolled 351 patients with newly diagnosed HCC treated with hepatectomy at The First Affiliated Hospital, Sun Yat-Sen University, Guangdong, China between 2006 and 2009. All specimens were histologically proven to be HCC after surgery. The routine workup was done within 7 days before surgery, which included a complete physical examination, hematological and biochemistry profiles, abdominal ultrasound and computed tomography (CT) or magnetic resonance imaging (MRI), chest X-ray or CT scan. Final diagnosis of HCC was made by pathological examination of biopsy specimens. All patients were $>18$ years of age, with complete clinical and laboratory data. No patients had any coexistent hematological disorders or known active infection before treatment, ensuring that the monocyte count was representative of the normal baseline value. In addition, patients with mixed HCC and cholangiocarcinoma and patients with no follow-up data were excluded. Informed consent was obtained, and procedures were carried out with prior approval of the Ethics Committee of the First Affiliated Hospital of Sun Yat-sen University (Guangzhou, China).

\section{Treatment and follow-up}

Hepatectomy was performed on all patients with intent to cure, and tumor thrombectomy or combined diaphragmatic resection was carried out when necessary. Surgical resection was defined as radical when there was no evidence of distant metastases and tumor clearance was both macroscopically and histologically complete. Patients were regularly followed up at outpatient clinics every 3 months for the first 2 years, every 6 months for the next 3 years, and once annually thereafter. Patients received a physical examination, liver ultrasound, chest X-ray and AFP test at each follow-up. Abdominal CT scan was performed every 6-12 months or when recurrence was suspected. Recurrence was defined as emergence of clinical, radiological, and/or pathological diagnosis (tissues obtained by ultrasound-guided fine-needle aspiration) of tumor. Once recurrence was confirmed, salvage treatments including re-operation, percutaneous ablation (ethanol injection, radiofrequency ablation, or microwave ablation) or TACE were selected as needed.

\section{Statistical analysis}

Statistical analysis was performed using SPSS for Windows version 16.0 (SPSS, Chicago, IL, USA). Receiver operating characteristic (ROC) curve analysis was performed to select the most appropriate cut-off value of monocyte count to stratify patients at a high risk of tumor recurrence. At each value, sensitivity and specificity were plotted, thus generating an ROC curve. The score closest to the point with both maximum sensitivity and specificity was selected as the cut-off value. The $x^{2}$ test was used to compare categorical variables. DFS and OS were calculated from the date of surgery to the date of recurrence, or HCC-associated death, respectively. Survival curves were plotted using the Kaplan-Meier method and compared using the log-rank test. The Cox proportional hazards model was used to determine independent prognostic factors on the basis of variables selected on univariate analysis. $P<0.05$ was considered significant.

\section{Results}

\section{Patient and tumor characteristics}

There were $310(88.3 \%)$ male and 41 (11.7\%) female patients. The mean age of patients was 50.1 years (range: 21-79 years). Two hundred and fifty-six patients (72.9\%) developed recurrence while 222 (63.2\%) died during follow-up. Hepatitis B surface antigen (HBsAg) was positive in 302 patients (86.0\%) and 269 (76.6\%) patients had underlying cirrhosis. Increased AFP (>200 ng/ml) was found in 190 cases $(54.1 \%)$ and $75(21.4 \%)$ patients had $\geq 2$ tumors in the liver. Mean tumor size (greatest dimension) was $89.0 \mathrm{~mm}$ (range: $10-300 \mathrm{~mm}$ ), with 281 (80.1\%) patients having tumors $>50 \mathrm{~mm}$. With regard to tumor differentiation according to Edmonson stage, there were 271 
(77.2\%) I/II stage and 80 (22.8\%) III/IV stage tumors. Macroscopic vessel invasion into the portal vein, hepatic vein or inferior vena cava was found in 90 patients (25.6\%). Details of features are shown in Table 1.

\section{Relationship between clinicopathological features and monocyte status}

The median monocyte count was $600 / \mathrm{mm}^{3}$, which was almost twice as high as the standard used by Sasaki et al. [9]. To exclude empirical bias, we used ROC curve analysis to determine the optimal cut-off value for elevated monocyte count. A cut-off value of $545 / \mathrm{mm}^{3}$ corresponded to the maximum joint sensitivity and specificity on the ROC plot (Figure 1). Clinicopathological features of patients with different monocyte status are summarized in Table 1. None of the commonly used clinicopathological features (age, gender, Edmonson grade, HBsAg status, surgical margin, capsulation, tumor number and cirrhosis) were significantly different between the two groups. However, patients with elevated monocyte counts tended to have larger tumors $(P=0.019)$.
Risk factors for prognosis of HCC after hepatectomy

For all patients, the 1-, 3- and 5-year DFS was 44\%, 30\% and $27 \%$, respectively, and the 1-, 3- and 5-year OS was $70 \%$, 43\%, 36\%, respectively. Univariate analysis (Table 2) revealed that macrovascular infiltration, monocyte counts $\geq 545 / \mathrm{mm}^{3}$, surgical margin $<1 \mathrm{~cm}$, AFP $\geq 200 \mathrm{ng} / \mathrm{ml}$, tumor size $\geq 5 \mathrm{~cm}$, non-capsulation (tumor had no capsulation or ruptured during surgery), multiple tumors, and macrovascular invasion were associated with significantly poorer DFS. Similarly, monocyte counts $\geq 545 / \mathrm{mm}^{3}$, surgical margin $<1 \mathrm{~cm}$, tumor size $\geq 5 \mathrm{~cm}$, non-capsulation, and multiple tumors predicted poor OS.

On multivariate analysis, four parameters including monocyte counts $\geq 545 / \mathrm{mm}^{3}$, tumor size $\geq 5 \mathrm{~cm}$, noncapsulation, and multiple tumors were independent prognostic factors of poor DFS and OS.

\section{DFS and OS according to monocyte status}

The 1-, 3- and 5-year DFS rate was 58\%, 41\% and 35\% for patients with monocyte counts $<545 / \mathrm{mm}^{3}$, and $36 \%, 23 \%$ and $21 \%$ for patients with monocyte counts $\geq 545 / \mathrm{mm}^{3}$,

Table 1 Comparison of clinicopathological features of patients with different monocyte counts

\begin{tabular}{|c|c|c|c|c|c|}
\hline \multirow[t]{2}{*}{ Category } & \multirow[t]{2}{*}{ Subcategory } & \multirow[t]{2}{*}{ Cases } & \multicolumn{2}{|c|}{ Monocytes $\left(/ \mathrm{mm}^{3}\right)$} & \multirow[t]{2}{*}{$P$ value } \\
\hline & & & $<545$ & $\geq 545$ & \\
\hline \multirow[t]{2}{*}{ Gender } & Male & 310 & 115 & 195 & 0.102 \\
\hline & Female & 41 & 20 & 21 & \\
\hline \multirow[t]{2}{*}{ Age } & $<50$ years & 268 & 102 & 166 & 0.418 \\
\hline & $\geq 50$ years & 83 & 33 & 50 & \\
\hline \multirow[t]{2}{*}{ HBsAg } & Negative & 49 & 14 & 35 & 0.083 \\
\hline & Positive & 302 & 121 & 181 & \\
\hline \multirow[t]{2}{*}{ AFP (ng/ml) } & $<200$ & 161 & 61 & 100 & 0.463 \\
\hline & $\geq 200$ & 190 & 74 & 116 & \\
\hline \multirow[t]{2}{*}{ Edmonson grading } & $|-| \mid$ & 271 & 107 & 164 & 0.278 \\
\hline & III-IV & 80 & 28 & 52 & \\
\hline \multirow[t]{2}{*}{ Tumor size } & $<5 \mathrm{~cm}$ & 70 & 35 & 35 & 0.019 \\
\hline & $\geq 5 \mathrm{~cm}$ & 281 & 100 & 181 & \\
\hline \multirow[t]{2}{*}{ Surgical margin } & $<1 \mathrm{~cm}$ & 122 & 44 & 78 & 0.289 \\
\hline & $\geq 1 \mathrm{~cm}$ & 229 & 91 & 138 & \\
\hline \multirow[t]{2}{*}{ Liver cirrhosis } & Absent & 82 & 29 & 53 & 0.3 \\
\hline & Present & 269 & 106 & 163 & \\
\hline \multirow[t]{2}{*}{ PVTT } & Absent & 278 & 108 & 170 & 0.44 \\
\hline & Present & 73 & 27 & 46 & \\
\hline \multirow[t]{2}{*}{ Capsulation } & Capsulated & 224 & 92 & 132 & 0.111 \\
\hline & Non-caspulated & 127 & 43 & 84 & \\
\hline \multirow[t]{2}{*}{ Tumor number } & Single & 276 & 107 & 169 & 0.465 \\
\hline & Multiple & 75 & 28 & 47 & \\
\hline \multirow[t]{2}{*}{ Macrovascular invasion } & Absent & 261 & 102 & 159 & 0.391 \\
\hline & Present & 90 & 33 & 57 & \\
\hline
\end{tabular}




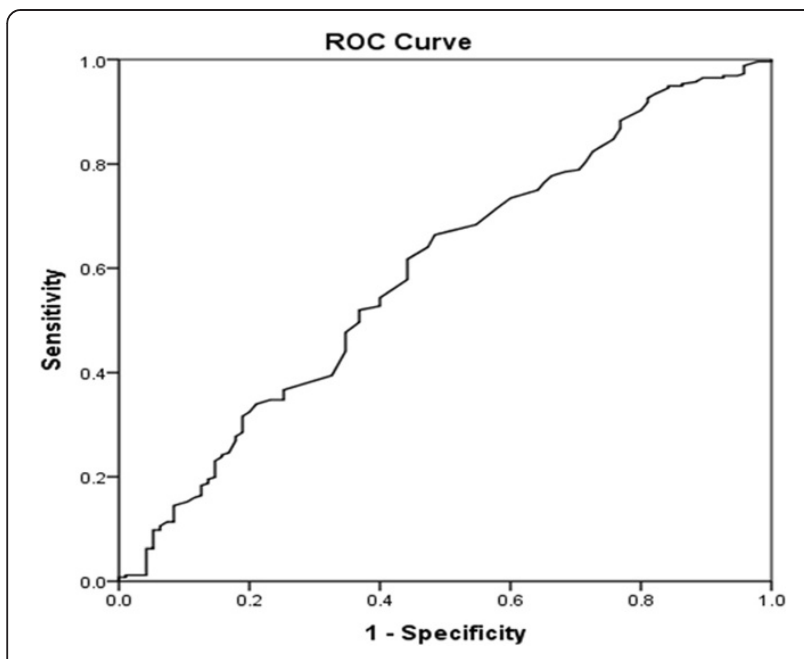

Figure 1 Receiver operating characteristic curve for determination of the cut-off value for monocyte in patients with hepatocellular carcinoma (HCC) after hepatic resection.

respectively $(P<0.001)$. Correspondingly, the 1-, 3- and 5year OS rate was $79 \%, 53 \%$ and $46 \%$ for patients with monocyte counts $<545 / \mathrm{mm}^{3}$, and $64 \%, 36 \%, 29 \%$ patients with monocyte counts $\geq 545 / \mathrm{mm}^{3}$. Both DFS and OS of patients with monocyte counts $<545 / \mathrm{mm}^{3}$ were significantly better than for patients with monocyte counts $\geq 545 / \mathrm{mm}^{3}(P<0.001)$ (Figure 2$)$.

\section{Subgroup analysis according to the HBV infection and cirrhosis status}

To clarify the subgroups of patients negatively influenced by preoperative peripheral blood monocyte counts, we classified patients according to accompanying liver disease (HBsAg positive, $n=302$; HBsAg negative, $n=49$ ) and underlying cirrhosis (cirrhosis, $n=269$; noncirrhosis, $n=82$ ). DFS after hepatic resection of HBVinfected patients was significantly better for those with a peripheral blood monocyte count $<545 / \mathrm{mm}^{3}(P<0.001)$, but DFS did not differ between patients without HBsAg infection within groups $(P=0.607)$. In contrast to the results of Sasaki et al., we found that DFS was significantly improved for the patients with a peripheral blood monocyte count $<545 / \mathrm{mm}^{3}$, whether or not cirrhosis was present $(P=0.002$ vs $P=0.018)$ (Figure 3$)$.

\section{Discussion}

We demonstrated that elevated monocyte count independently predicted worse survival in HCC patients treated with hepatic resection, which concurs with a previous study by Sasaki et al. [9]. In addition, tumor size $\geq 5 \mathrm{~cm}$, non-capsulation, and multiple tumors were also independent prognostic factors of poor DFS and OS.

Numerous clinical and experimental studies have indicated that inflammation is a critical component of tumor progression. Inflammatory markers such as C-reactive protein have been suggested as surrogate markers for HCC [8]. Likewise, subsets of peripheral blood cells have been found to be predictors of prognosis. Elevated NLR was shown to be an indicator of poor outcome in patients undergoing hepatic resection for colorectal liver metastasis and curative resection for HCC $[14,15]$. An elevated neutrophil, monocyte or leukocyte count was associated with poor survival in patients with metastatic melanoma [12]. In addition, a higher pretreatment circulating monocyte count was independently associated with poor prognosis in patients with locally advanced cervical squamous cell carcinoma and HCC $[9,10]$. However, in all of these studies, the cut-off value for monocyte count was based on a median value of circulating monocyte count [10]. In the present study, the median monocyte count was two times higher than that of Sasaki et al. To exclude empirical bias, we used ROC curve to determine the optimal cut-off value to predict $\mathrm{HCC}$ recurrence after hepatectomy.

Monocyte count can be easily measured by routine preoperative blood workup and is a strong prognostic factor for a number of malignancies, such as colorectal cancer with liver metastasis and melanoma. With regard to HCC, Sasaki et al. first reported that monocyte count was a useful prognostic indicator in HCC patients [9]. In that study, a preoperative absolute peripheral blood monocyte count $>300 / \mathrm{mm}^{3}$ was shown to be an independent prognostic indicator of tumor recurrence, especially in patients with HCC accompanying liver cirrhosis [9]. In their series, serum hepatitis $\mathrm{C}$ antibody was positive in $100(65.4 \%)$ of the 153 tested patients and HBV infection was positive in only $23.74 \%(47 / 198)$ patients, which was different from our data $(86 \%, 302 /$ 351 patients). From subgroup analysis we found that elevated monocyte predicted early recurrence whether or not cirrhosis was present, which was different from the study of Sasaki et al. Patients in these two studies have a different background of cirrhosis, which might account for the difference. In addition, we found that elevated monocyte count predicted poor prognosis in HBVpositive HCC patients, but not in negative ones. This is a novel finding.

The present study confirms that preoperative monocyte count is an independent prognostic factor for HCC, especially in patients with an HBV background. After surgery, too many factors influence postoperative peripheral blood monocyte count, such as bleeding, shortage or overuse of liquid replacement, and sepsis. Therefore, postoperative peripheral blood inflammatory cells have not been used often to predict prognosis as the preoperative counterparts, although there are a few such reports [16-18]. In fact, in the study of Lee et al., monocyte count significantly increased after surgery, but the authors did 
Table 2 Univariate and multivariate analysis of clinicopathological parameters influencing prognosis

\begin{tabular}{|c|c|c|c|c|c|c|c|}
\hline \multirow[t]{2}{*}{ Category } & \multirow[t]{2}{*}{ Subcategory } & \multicolumn{2}{|c|}{ Disease-free survival } & \multirow[b]{2}{*}{$\mathrm{HR}(95 \% \mathrm{Cl})$} & \multicolumn{2}{|c|}{ Overall survival } & \multirow[b]{2}{*}{$\mathrm{HR}(95 \% \mathrm{Cl})$} \\
\hline & & $\begin{array}{l}\text { Univariate } \\
\text { analysis }\end{array}$ & $\begin{array}{l}\text { Multivariate } \\
\text { analysis }\end{array}$ & & $\begin{array}{l}\text { Univariate } \\
\text { analysis }\end{array}$ & $\begin{array}{l}\text { Multivariate } \\
\text { analysis }\end{array}$ & \\
\hline \multirow[t]{2}{*}{ Gender } & Male & 0.25 & & & 0.064 & & \\
\hline & Female & & & & & & \\
\hline \multirow[t]{2}{*}{ Age } & $<50$ years & 0.079 & & & 0.078 & & \\
\hline & $\geq 50$ years & & & & & & \\
\hline \multirow[t]{2}{*}{$\mathrm{HBs}-\mathrm{Ag}$} & Negative & 0.412 & & & 0.978 & & \\
\hline & Positive & & & & & & \\
\hline \multirow[t]{2}{*}{ AFP (ng/ml) } & $<200$ & 0.021 & & & 0.209 & & \\
\hline & $\geq 200$ & & & & & & \\
\hline \multirow[t]{2}{*}{ Edmonson grading } & $|-| \mid$ & 0.277 & & & 0.788 & & \\
\hline & $\mathrm{III-IV}$ & & & & & & \\
\hline \multirow[t]{2}{*}{ Tumor size } & $<5 \mathrm{~cm}$ & $<0.001$ & $<0.001$ & $1.991(1.383-2.867)$ & 0.001 & $<0.001$ & $1.919(1.291-2.582)$ \\
\hline & $\geq 5 \mathrm{~cm}$ & & & & & & \\
\hline \multirow[t]{2}{*}{ Surgical margin } & $<1 \mathrm{~cm}$ & 0.001 & & & 0.002 & & \\
\hline & $\geq 1 \mathrm{~cm}$ & & & & & & \\
\hline \multirow[t]{2}{*}{ Liver cirrhosis } & Absent & 0.505 & & & 0.91 & & \\
\hline & Present & & & & & & \\
\hline \multirow[t]{2}{*}{ Monocyte count $\left(/ \mathrm{mm}^{3}\right)$} & $<545$ & $<0.001$ & 0.01 & $1.393(1.083-1.793)$ & $<0.001$ & 0.002 & $1.578(1.187-2.097)$ \\
\hline & $\geq 545$ & & & & & & \\
\hline \multirow[t]{2}{*}{ PVTT } & Absent & 0.545 & & & 0.911 & & \\
\hline & Present & & & & & & \\
\hline \multirow[t]{2}{*}{ Capsulation } & Capsulated & $<0.001$ & $<0.001$ & $1.597(1.231-2.071)$ & 0.002 & $<0.001$ & $1.793(1.371-2.345)$ \\
\hline & Non-caspulated & & & & & & \\
\hline \multirow[t]{2}{*}{ Tumor number } & Single & $<0.001$ & 0.005 & 1.513 (1.134-2.019) & $<0.001$ & $<0.001$ & $1.771(1.312-2.392)$ \\
\hline & Multiple & & & & & & \\
\hline \multirow[t]{2}{*}{ Macrovascular invasion } & Absent & 0.012 & & & 0.086 & & \\
\hline & Present & & & & & & \\
\hline
\end{tabular}

$\mathrm{Cl}$, confidence interval; $H R$, hazard ratio.

not detect significant effects on circulating monocytes and survival [18]. We think it might be unsuitable to use postoperative monocyte count to predict prognosis for too many confounding factors.

The exact pathophysiology for the association between high monocyte counts and poor prognosis is not well understood. There are several possible explanations. First, it has been hypothesized that activation of the innate immune system through mobilization of monocytes to tissue macrophages develops an inflammatory state associated with increased risk of cancer and mortality [19-21]. Tumor-associated macrophages (TAMs), which arise from blood monocytes, appear to play a crucial role in the tumor microenvironment and can educate and control invading leukocytes to promote angiogenesis, viability, motility and invasion [19-21]. Monocytes are actively attracted to the tumor site and differentiate into TAMs as a result of the production of cytokines and chemokines by tumor cells, such as monocyte chemoattractant protein-1 [or chemokine CC ligand (CCL2)], RANTES (or CCL5) and vascular endothelial growth factor. TAMs are not only capable of killing tumor cells and releasing angiostatic compounds, but can exert pro-tumor effects through the secretion of immunosuppressive cytokines and angiogenic factors. Unfortunately, the pro-tumor effects of TAMs often outweigh the tumor-inhibiting effects during tumor development. The number of TAMs has been shown to correlate with poor prognosis [19-22]. Second, elevated $\mathrm{CD} 14^{+} \mathrm{CD} 16^{+}$ monocytes (a minor blood monocyte subpopulation) correlate with TAM infiltration. These monocytes express higher levels of adhesion molecules and scavenger receptors, which enable them to adhere to endothelial cells, and they also express high levels of growth-factor- and angiogenic-factor-related genes. All these characteristics indicate that $\mathrm{CD} 14^{+} \mathrm{CD} 16^{+}$monocytes have protumorigenic 


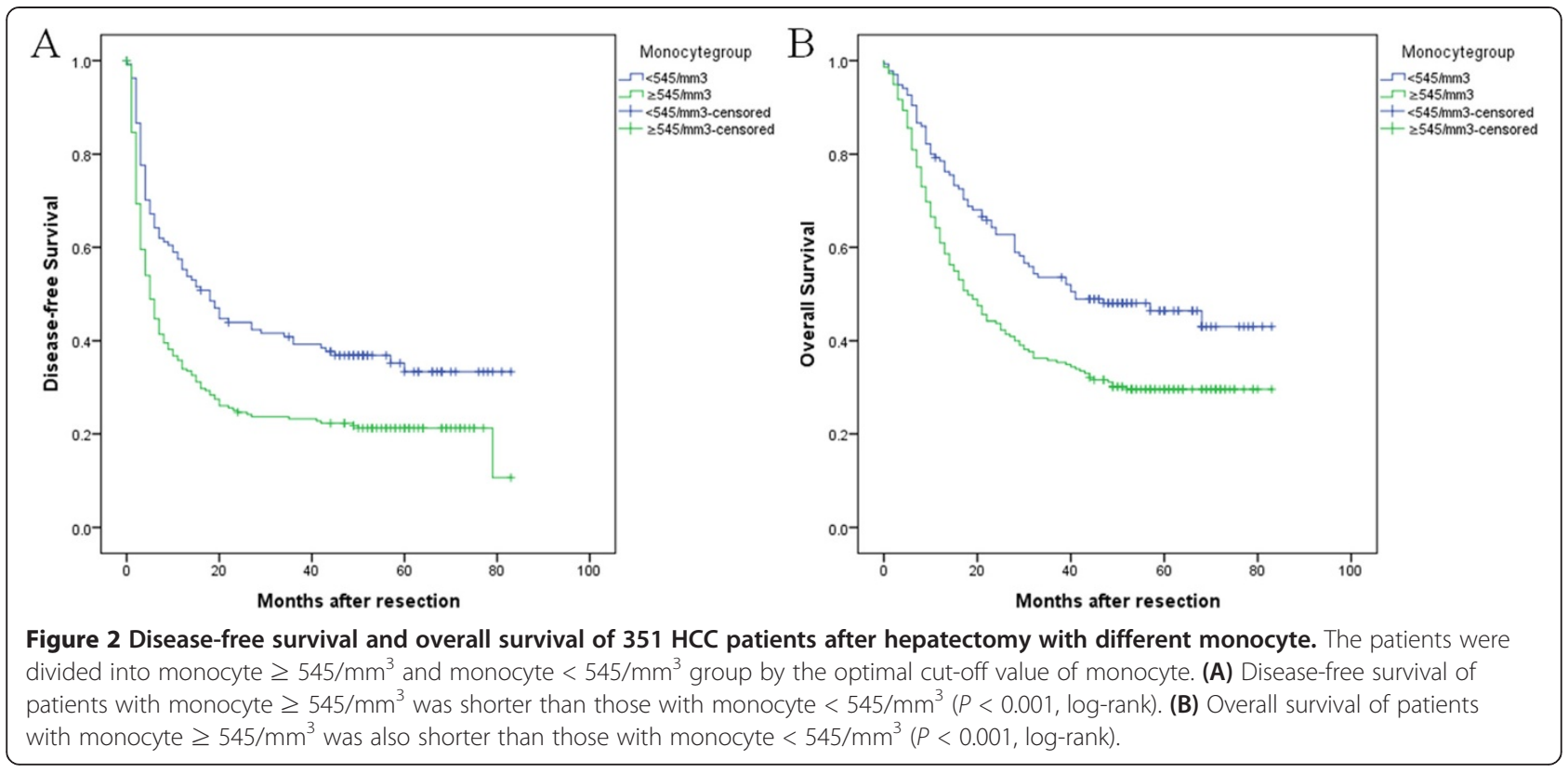

features and might be associated with rapid tumor progression and poor patient outcome [23]. Third, a fraction of monocytes/macrophages in peritumoral stroma expresses surface programmed death ligand (PD-L) 1 molecules in tumors from patients with HCC. The PD-L1 ${ }^{+}$monocytes effectively suppress tumor-specific $\mathrm{T}$ cell immunity and contribute to the growth of human tumors in vivo, which can be reversed by blocking PD-L1 on these monocytes. Moreover, PD-L1 expression on tumor-infiltrating monocytes is increased with disease progression, and the intensity of the protein is associated with high mortality and reduced survival in HCC patients. Thus, expression of PDL1 on activated monocytes/macrophages may represent a novel mechanism that links the proinflammatory response to immune tolerance in the tumor milieu [24]. In short, monocytes might contribute to the compromised antitumor microenvironment, thus promoting tumor progress.

HCC shows low responsiveness to standard chemotherapeutic agents or radiotherapy, like other tumors (such as osteosarcoma, lung cancer, and breast cancer). Therefore, a high preoperative monocyte count does not necessitate neoadjuvant therapy [25-27]. Instead, postoperative adjuvant therapy might be considered. Nevertheless, for HCC patients after curative resection, there is no consensus on the use of adjuvant therapy outside of clinical trials [3]. However, studies have shown that HCC patients with a high risk of recurrence are likely to benefit from postoperative adjuvant treatment such as chemotherapy, TACE, or antiviral therapy [28,29]. A study from Xia et al. [30] showed that adjuvant therapy with capecitabine postponed recurrence of HCC after curative resection. In addition, an adjuvant intraportal venous chemotherapy regimen of cisplatin, interferon- $\alpha$, doxorubicin, and 5-fluorouracil (PIAF) for HCC patients with portal vein tumor thrombus (PVTT) following hepatectomy, plus portal thrombectomy, significantly delayed recurrence and prolonged survival [31]. Risk of HCC recurrence after potentially curative resection was higher in the setting of high viral replication and ongoing inflammatory activity in the liver. In a metaanalysis, antiviral therapy with interferon was found to improve 1-, 2- and 3-year recurrence-free survival by $7.8 \%$, $35.4 \%$ and $14.0 \%$, respectively (all $P<0.01$ ) [32]. Likewise, oral antiviral drugs (including lamivudine, adefovir and entecavir) showed potential beneficial effects after curative treatment of HBV-related HCC in terms of tumor recurrence, liver-related mortality, and OS [33,34]. Although it remains unclear whether TACE actually decreases the risk of tumor recurrence, it has been reported that postoperative TACE prevents early recurrence, while antiviral therapy prevents late recurrence of HCC. Combination of antiviral therapy and TACE is suggested for prevention in HCC patients at high risk of recurrence $[28,29,35]$. Multicenter studies evaluating the effects of adjuvant kinase inhibitor treatments with sorafenib after curative resection or tumor ablation are currently underway (STORM study from Bayer) [4]. Until the results of these studies are available, the role of adjuvant or neoadjuvant treatments with kinase inhibitors in the prevention of tumor recurrence in the setting of potentially curative treatments for HCC remains unknown.

There were two limitations to our study. First, we were not able to split our data set into a training data set and a test data set for statistical validation because of the small number of patients, which we hope to validate in future 


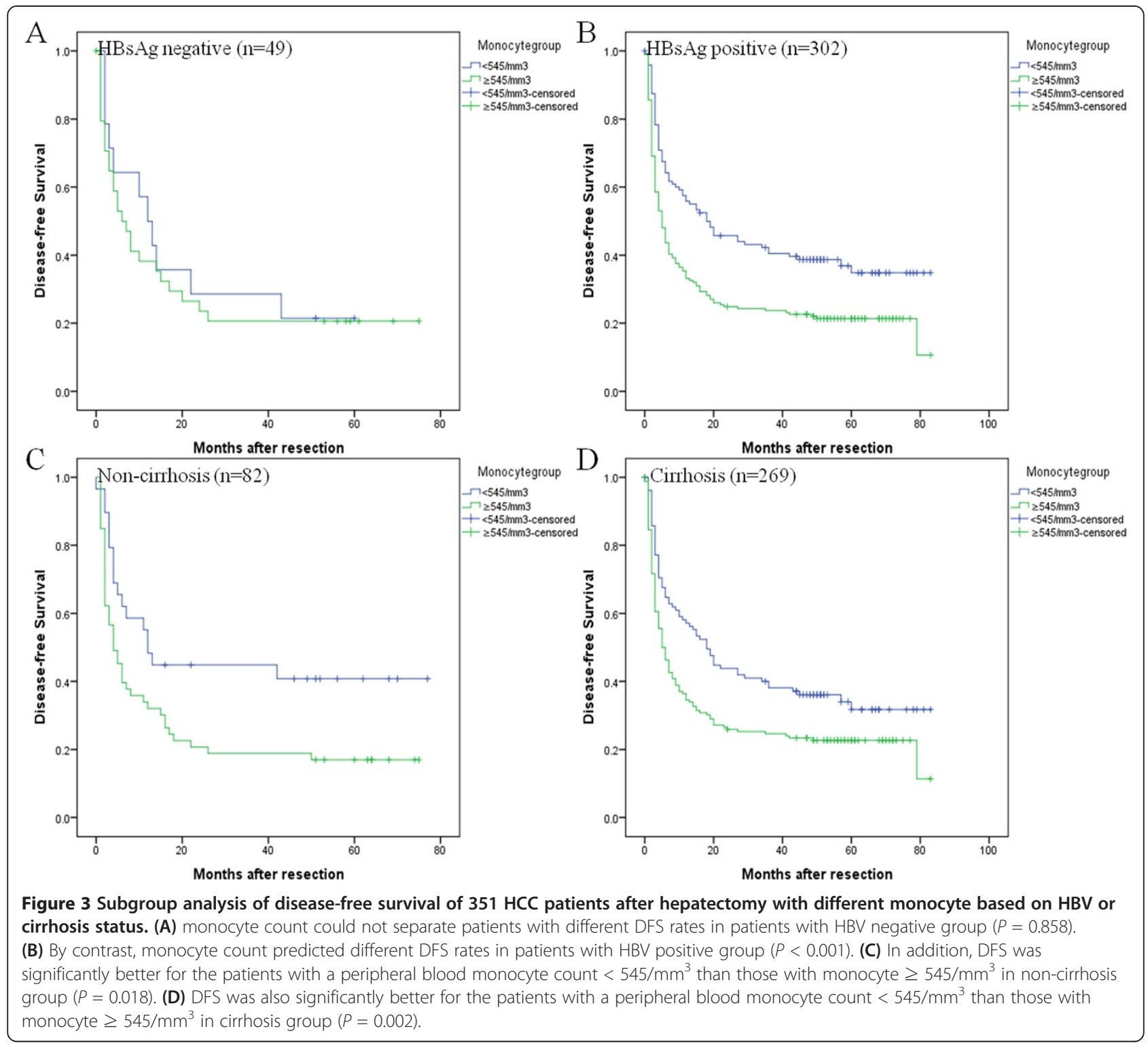

studies, or from other centers. Second, although we found that elevated monocyte count predicted early recurrence, and that these patients might benefit from postoperative adjuvant therapy, we were not able to test this hypothesis, which we hope to prove in future clinical trials.

\section{Conclusions}

Our results show that the absolute number of peripheral blood monocytes may be related to tumor progression and is an independent risk factor for recurrence of HCC after hepatic resection, especially for patients with HBV infection. Future clinical trials to test the efficacy of postoperative adjuvant treatment in HCC patients with an elevated preoperative monocyte count might be considered.

\section{Abbreviations}

AFP: a-fetoprotein; CT: Computed tomography; DFS: Disease-free survival; GPS: Glasgow prognostic score; HBV: Hepatitis B virus; HCC: Hepatocellular carcinoma; MRI: Magnetic resonance imaging; NLR: Neutrophil lymphocyte ratio; OS: Overall survival; PIAF: Cisplatin, interferon-a, doxorubicin, and 5-fluorouracil; PLR: Platelet lymphocyte ratio; PVTT: Portal vein tumor thrombus; ROC: Receiver operating characteristic; TACE: Transcatheter arterial chemoembolization; TAM: Tumor-associated macrophage.

\section{Competing interests}

The authors declare that they have no competing interests.

\section{Authors' contributions}

SLS, SJF and BGP were the main authors of the manuscript. They were involved in the conception, design and coordination of the study as well as in data analysis, interpretation of results and drafting the manuscript. BGP was in charge of all experimental procedures. XQH, BC, MK, SQL, YPH, and $\sqcup L$ participated in the experimental procedures and revised critically the content of the manuscript. XQH provided anesthesiology, and carried out the clinical data collection. All authors contributed to the interpretation of data and critically revised the manuscript. All authors read and approved the final manuscript. 


\section{Acknowledgments}

This study was funded by the grants of the National Natural Science Foundation of China (Nos. 81172039 and 81302142) and the Science and Technology Key Project of Guangdong Province (No. 2010B031500026). The funders had no role in study design, data collection and analysis, decision to publish, or preparation of the manuscript. We thank Professor Stephen Tomlinson from the Department of Microbiology and Immunology, Medical University of South Carolina, for review and correction of the manuscript.

\section{Author details}

'Department of Hepatobiliary Surgery, The First Affiliated Hospital, Sun Yat-sen University, Guangzhou 510080, China. ${ }^{2}$ Department of Hepatopancreatobiliary Surgery, The Scecond Affiliated Hospital of Guangzhou University of Chinese Medicine, Guangzhou 510120, China. ${ }^{3}$ Department of Anesthesiology, The First Affiliated Hospital, Sun Yat-sen University, Guangzhou 510080, China.

Received: 7 April 2014 Accepted: 25 September 2014 Published: 3 October 2014

\section{References}

1. El-Serag HB: Epidemiology of viral hepatitis and hepatocellular carcinoma. Gastroenterology 2012, 142(6):1264-1273. e1.

2. Forner A, Llovet JM, Bruix J: Hepatocellular carcinoma. Lancet 2012, 379(9822):1245-1255.

3. Kobayashi T, Ishiyama $\mathrm{K}$, Ohdan $\mathrm{H}$ : Prevention of recurrence after curative treatment for hepatocellular carcinoma. Surg Today 2013, 43(12):1347-1354.

4. Schlitt HJ, Schnitzbauer AA: Hepatocellular carcinoma: agents and concepts for preventing recurrence after curative treatment. Liver Transpl 2011, 17(Suppl 3):S10-S12.

5. McMillan DC: Systemic inflammation, nutritional status and survival in patients with cancer. Curr Opin Clin Nutr Metab Care 2009, 12(3):223-226.

6. Gomez D, Farid S, Malik HZ, Young AL, Toogood GJ, Lodge JP, Prasad KR: Preoperative neutrophil-to-lymphocyte ratio as a prognostic predictor after curative resection for hepatocellular carcinoma. World J Surg 2008, 32(8):1757-1762.

7. Wang GY, Yang Y, Li H, Zhang J, Jiang N, Li MR, Zhu HB, Zhang Q, Chen GH: A scoring model based on neutrophil to lymphocyte ratio predicts recurrence of HBV-associated hepatocellular carcinoma after liver transplantation. PLoS One 2011, 6(9):e25295

8. Kim JM, Kwon CH, Joh JW, Ko JS, Park JB, Lee JH, Kim SJ, Paik SW, Park CK: C-reactive protein may be a prognostic factor in hepatocellular carcinoma with malignant portal vein invasion. World J Surg Oncol 2013, 11:92

9. Sasaki A, Iwashita Y, Shibata K, Matsumoto T, Ohta M, Kitano S: Prognostic value of preoperative peripheral blood monocyte count in patients with hepatocellular carcinoma. Surgery 2006, 139(6):755-764.

10. Lee $Y Y$, Choi CH, Sung CO, Do IG, Huh S, Song T, Kim MK, Kim HJ, Kim TJ, Lee JW, Kim BG, Bae DS: Prognostic value of pre-treatment circulating monocyte count in patients with cervical cancer: comparison with SCC-Ag level. Gynecol Oncol 2012, 124(1):92-97.

11. Sasaki A, Kai S, Endo Y, Iwaki K, Uchida H, Tominaga M, Okunaga R, Shibata K, Ohta M, Kitano S: Prognostic value of preoperative peripheral blood monocyte count in patients with colorectal liver metastasis after liver resection. J Gastrointest Surg 2007, 11(5):596-602.

12. Schmidt H, Bastholt L, Geertsen P, Christensen IJ, Larsen S, Gehl J, der Maase HV: Elevated neutrophil and monocyte counts in peripheral blood are associated with poor survival in patients with metastatic melanoma: a prognostic model. Br J Cancer 2005, 93(3):273-278

13. Sajadieh A, Mouridsen MR, Selmer C, Intzilakis T, Nielsen OW, Haugaard SB: Monocyte number associated with incident cancer and mortality in middle-aged and elderly community-dwelling Danes. Eur J Cancer 2011, 47(13):2015-2022.

14. Halazun KJ, Aldoori A, Malik HZ, Al-Mukhtar A, Prasad KR, Toogood GJ, Lodge JP: Elevated preoperative neutrophil to lymphocyte ratio predicts survival following hepatic resection for colorectal liver metastases. Eur J Surg Oncol 2008, 34(1):55-60

15. Limaye AR, Clark V, Soldevila-Pico C, Morelli G, Suman A, Firpi R, Nelson DR Cabrera R: Neutrophil-lymphocyte ratio predicts overall and recurrence- free survival after liver transplantation for hepatocellular carcinoma. Hepatol Res 2012, doi:10.1111/hepr.12019.

16. Dan J, Zhang Y, Peng Z, Huang J, Gao H, Xu L, Chen M: Postoperative neutrophil-to-lymphocyte ratio change predicts survival of patients with small hepatocellular carcinoma undergoing radiofrequency ablation. PLoS One 2013, 8(3):e58184

17. Iwase R, Shiba H, Haruki K, Fujiwara Y, Furukawa K, Futagawa Y, Wakiyama S, Misawa T, Yanaga K: Post-operative lymphocyte count may predict the outcome of radical resection for gallbladder carcinoma. Anticancer Res 2013, 33(8):3439-3444

18. Lee YY, Choi CH, Sung CO, Do IG, Hub SJ, Kim HJ, Kim TJ, Lee JW, Bae DS, Kim BG: Clinical significance of changes in peripheral lymphocyte count after surgery in early cervical cancer. Gynecol Oncol 2012 127(1):107-113.

19. Dirkx AE, Oude EMG, Wagstaff J, Griffioen AW: Monocyte/macrophage infiltration in tumors: modulators of angiogenesis. J Leukoc Biol 2006, 80(6):1183-1196.

20. Heusinkveld M, van der Burg SH: Identification and manipulation of tumor associated macrophages in human cancers. J Trans/ Med 2011, 9:216.

21. Mantovani A, Germano G, Marchesi F, Locatelli M, Biswas SK: Cancer-promoting tumor-associated macrophages: new vistas and open questions. Eur J Immunol 2011, 41(9):2522-2525

22. Shirabe K, Mano Y, Muto J, Matono R, Motomura T, Toshima T, Takeishi K, Uchiyama H, Yoshizumi T, Taketomi A, Morita M, Tsujitani S, Sakaguchi Y, Maehara Y: Role of tumor-associated macrophages in the progression of hepatocellular carcinoma. Surg Today 2012, 42(1):1-7.

23. Subimerb C, Pinlaor S, Lulitanond V, Khuntikeo N, Okada S, McGrath MS, Wongkham S: Circulating CD14(+) CD16(+) monocyte levels predict tissue invasive character of cholangiocarcinoma. Clin Exp Immunol 2010, 161(3):471-479.

24. Kuang DM, Peng C, Zhao Q, Wu Y, Chen MS, Zheng L: Activated monocytes in peritumoral stroma of hepatocellular carcinoma promote expansion of memory T helper 17 cells. Hepatology 2010, 51(1):154-164.

25. Collins M, Wilhelm M, Conyers R, Herschtal A, Whelan J, Bielack S, Kager L, Kuhne T, Sydes M, Gelderblom H, Ferrari S, Picci P, Smeland S, Eriksson M, Petrilli AS, Bleyer A, Thomas DM: Benefits and adverse events in younger versus older patients receiving neoadjuvant chemotherapy for osteosarcoma: findings from a meta-analysis. J Clin Oncol: Official J Am Soc Clin Oncol 2013, 31(18):2303-2312.

26. McElnay P, Lim E: Adjuvant or neoadjuvant chemotherapy for NSCLC. J Thorac Dis 2014, 6(Suppl 2):S224-S227.

27. Houssami N, Macaskill P, Von MG, Marinovich ML, Mamounas E: Meta-analysis of the association of breast cancer subtype and pathologic complete response to neoadjuvant chemotherapy. Eur $J$ Cancer (Oxford, Eng: 1990) 2012, 48(18):3342-3354.

28. Peng BG, He Q, Li JP, Zhou F: Adjuvant transcatheter arterial chemoembolization improves efficacy of hepatectomy for patients with hepatocellular carcinoma and portal vein tumor thrombus. Am J Surg 2009, 198(3):313-318

29. Yan O, Ni J, Zhang GL, Yao X, Yuan WB, Zhou L, Zheng SS: Efficacy of postoperative antiviral combined transcatheter arterial chemoembolization therapy in prevention of hepatitis B-related hepatocellular carcinoma recurrence. Chin Med J (Engl) 2013, 126(5):855-859.

30. Xia Y, Qiu Y, Li J, Shi L, Wang K, Xi T, Shen F, Yan Z, Wu M: Adjuvant therapy with capecitabine postpones recurrence of hepatocellular carcinoma after curative resection: a randomized controlled trial. Ann Surg Oncol 2010, 17(12):3137-3144.

31. Liang LJ, Hu WJ, Yin XY, Zhou Q, Peng BG, Li DM, Lu MD: Adjuvant intraportal venous chemotherapy for patients with hepatocellular carcinoma and portal vein tumor thrombi following hepatectomy plus portal thrombectomy. World J Surg 2008, 32(4):627-631.

32. Shen YC, Hsu C, Chen LT, Cheng CC, Hu FC, Cheng AL: Adjuvant interferon therapy after curative therapy for hepatocellular carcinoma (HCC): a meta-regression approach. J Hepatol 2010, 52(6):889-894.

33. Wong JS, Wong GL, Tsoi KK, Wong WW, Cheung SY, Chong CN, Wong J, Lee KF, Lai PB, Chan HL: Meta-analysis: the efficacy of anti-viral therapy in prevention of recurrence after curative treatment of chronic hepatitis B-related hepatocellular carcinoma. Aliment Pharmacol Ther 2011, 33(10):1104-1112. 
34. Hosaka T, Suzuki F, Kobayashi M, Seko Y, Kawamura Y, Sezaki H, Akuta N, Suzuki Y, Saitoh S, Arase Y, Ikeda K, Kobayashi M, Kumada H: Long-term entecavir treatment reduces hepatocellular carcinoma incidence in patients with hepatitis B virus infection. Hepatology (Baltimore, Md) 2013, 58(1):98-107.

35. Li Q, Wang J, Sun Y, Cui YL, Juzi JT, Li HX, Qian BY, Hao XS: Efficacy of postoperative transarterial chemoembolization and portal vein chemotherapy for patients with hepatocellular carcinoma complicated by portal vein tumor thrombosis-a randomized study. World J Surg 2006, 30(11):2004-2011. discussion 2012-2013.

doi:10.1186/1471-2407-14-744

Cite this article as: Shen et al: Elevated preoperative peripheral blood monocyte count predicts poor prognosis for hepatocellular carcinoma after curative resection. BMC Cancer 2014 14:744.

\section{Submit your next manuscript to BioMed Central and take full advantage of:}

- Convenient online submission

- Thorough peer review

- No space constraints or color figure charges

- Immediate publication on acceptance

- Inclusion in PubMed, CAS, Scopus and Google Scholar

- Research which is freely available for redistribution 